\title{
Ultrastructure of Gonadotropin-Releasing Hormone Neuronal Structures Derived from Normal Fetal Preoptic Area and Transplanted into Hypogonadal Mutant (hpg) Mice
}

\author{
A. J. Silverman, ${ }^{\star}$ E. A. Zimmerman, $\nmid$ G. J. Kokoris, $\ddagger$ and M. J. Gibson $\ddagger$ \\ *Department of Anatomy and Cell Biology, Columbia University, New York, New York 10032, †Department of \\ Neurology, Oregon Health Sciences University, Portland, Oregon 97201, and \$Department of Medicine, Division \\ of Endocrinology, Mount Sinai School of Medicine, New York, New York 10029
}

\begin{abstract}
The hpg mutant mouse lacks the neurohormone gonadotropinreleasing hormone (GnRH) and hence has a reproductive deficit. This deficit can be corrected by placement of normal fetal preoptic area into the third ventricle (see Krieger et al., 1985). We have now used ultrastructural immunocytochemistry to investigate the morphology of GnRH neurons in such intraventricular grafts, the routes that their axons take as they exit into the host, and the neurosecretory terminations that they make in the host median eminence. The GnRH cells in the transplant were similar in morphology to that reported for such cells in the preoptic area of other rodents. There was a large central nucleus, frequently indented and containing 1 or 2 nucleoli. The thin rim of cytoplasm was filled with rough endoplasmic reticulum, Golgi stacks, and mitochondria. Both dendritic and axonal profiles were identified, and a modest synaptic input to the former was found. Between the host and the implant a complex multilayered ependymal zone developed, and it was through this region that GnRH axons exited into the host arcuate nucleus and median eminence, usually surrounded by ependymal or glial elements. Within the median eminence, GnRH terminals were in close association with fenestrated blood vessels forming a normal neurosecretory terminus.
\end{abstract}

The mutant hypogonadal ( $h p g$ ) mouse has an underdeveloped pituitary-gonadal system as a result of a deficiency in the neurohormone gonadotropin-releasing hormone (GnRH) (Cattanach et al., 1977). Light-microscopic immunocytochemical observations indicate that no GnRH neurons are present in the brain of this mutant (Silverman et al., 1985), while genetic analysis suggests that at least 2 exons are missing from the GnRH gene (Seeburg, personal communication). When placed in the third ventricle, grafts of normal fetal preoptic area-the region containing the majority of GnRH neurons in rodents (Witkin et al., 1982) - can reverse the endocrine deficiencies of both male (Krieger et al., 1982) and female (Gibson et al., 1984a) hpg hosts. In females receiving such replacement therapy, mating behavior and successful pregnancies can occur (Gibson et al., 1984b). Grafts generally contain a relatively small number of $\mathrm{GnRH}$ neurons, but $\mathrm{GnRH}$ fibers can exit into the host arcuate nucleus and median eminence (Silverman et al., 1985). Such fibers appeared to be in intimate contact with the portal capillaries in

\footnotetext{
Received Oct. 21, 1985; revised Dec. 23, 1985; accepted Dec. 30, 1985.

We would like to acknowledge the guidance and help of our collaborator, Dr. Dorothy Krieger, whose untimely death occurred while this work was in progress.

This work was supported by USPHS Grant NS 20335. We would like to thank Ms. Katharine Bock for her excellent technical assistance.

Correspondence should be addressed to Ann-Judith Silverman, Department of Anatomy and Cell Biology, Columbia University, 630 West 168th Street, New York, NY 10032.

Copyright (C) 1986 Society for Neuroscience $0270-6474 / 86 / 072090-07 \$ 02.00 / 0$
}

the host median eminence, one of their normal targets. In the present study we have used electron-microscopic immunocytochemistry to determine the ultrastructural appearance of such neurons within the graft and the nature of the relationship of their axons to host tissue.

\section{Materials and Methods}

Three male hpg hosts 6 months of age were used in this study. Each host received implants of preoptic aareas from 2 normal $16-18 \mathrm{~d}$ fetuses as previously described (Krieger et al., 1982). Hosts survived for 120 d postimplantation, at which time they were anesthetized with sodium pentobarbital and perfused transcardially with $4 \%$ paraformaldehyde, $0.1 \%$ glutaraldehyde in a $0.1 \mathrm{M}$ phosphate buffer (approximately 150 $\mathrm{ml}$ ). Brain tissue was immersed in the same fixative for $2 \mathrm{hr}$. At the time of sacrifice, testes were removed and weighed. A separate group $(n=5)$ of $h p g$ males of the same age but without transplants was also sacrificed and testicular weights determined.

Blocks of tissue containing the transplant and the host median eminence were sectioned at $50 \mu \mathrm{m}$ on a Vibratome (Lancer) and processed for ultrastructural immunocytochemistry using the LR-1 antiserum, a generous gift of Robert Benoit (Silverman, 1984). Localization of the antigen was carried out using a commercial biotinylated second antibody and an avidin-biotin-HRP complex (Vector Laboratories). The HRP was demonstrated with a cobalt chloride enhancement of the diaminobenzidine reaction product and using glucose and glucose oxidase to generate the hydrogen peroxide substrate (see Oldfield et al., 1983). Absorption controls were carried out at the light-microscopic level on tissue sections of both normal mice and hpg mice with normal tissue transplants. Addition of $100 \mathrm{ng}$ of luteinizing hormone-releasing hormone (LHRH) (Pennisula Laboratories) to $1 \mathrm{ml}$ of diluted antiserum $24 \mathrm{hr}$ prior to its use on the tissue eliminated all staining. In radioimmunoassay the antigenic determinant consists of amino acids $3,4,7$, 8,9 , and 10 of the decapeptide (R. Benoit, personal communication).

Regions containing reaction product were identified and dissected prior to osmification with $2 \%$ osmium tetroxide containing $1.5 \%$ potassium ferricyanide in $0.9 \% \mathrm{NaCl}$. Care was taken to maintain an orientation that permitted identification of host and transplanted tissue. Tissue was embedded in Epon 812 and $1 \mu \mathrm{m}$ sections used to identify areas containing reaction product. Such positive structures were then found in the ultrathin sections in the EM.

\section{Results}

At the time of sacrifice, mean testicular weights $( \pm S D)$ in animals with transplants were significantly larger than those of $h p g$ mice of the same age $(50.4 \pm 7.8$ vs $7.5 \pm 1.0)$ but were slightly smaller than those previously reported by us in animals receiving a transplant for a similar duration (Silverman et al., 1985). Nonetheless, these weights are well within the range indicative of a "successful" transplant, i.e., one resulting in functional recovery of the reproductive tract. GnRH-positive neurons were present in the transplant of all 3 animals, and $\mathrm{CnRH}$ fibers could be observed in the median eminence. Neither in these animals nor in the others in which transplants were confined to 


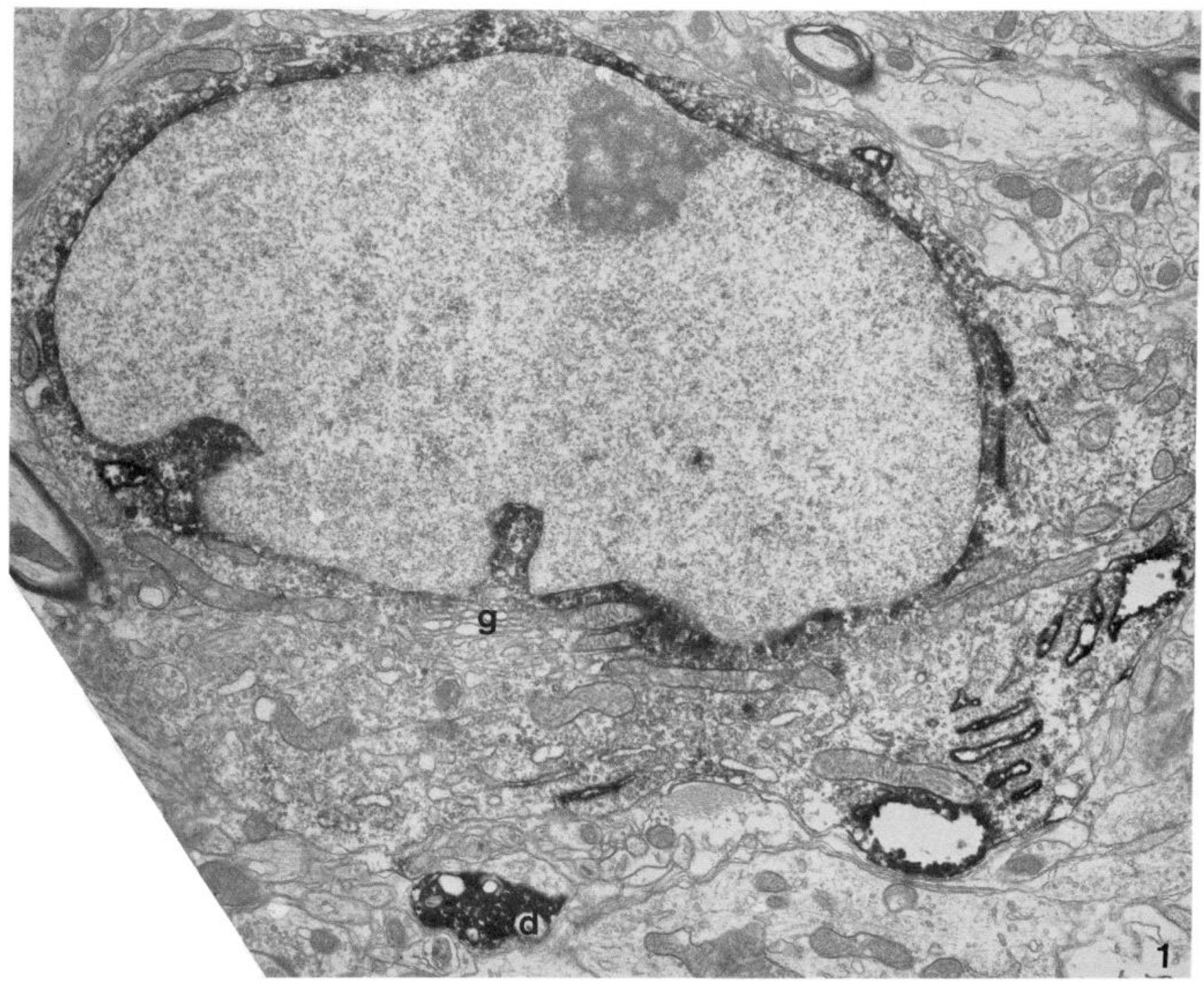

Figure 1. Typical GnRH neuron within a graft growing in the third ventricle of an hpg male mouse. The large central nucleus is indented in several places and has a large nucleolus. Reaction product is associated with stacks of the rough endoplasmic reticulum but not the Golgi $(G)$ complex. $\times 15,000$.

the third ventricle (Silverman et al., 1985) did GnRH fibers contact inappropriate targets.

\section{Transplant}

At the ultrastructural level, GnRH-positive neurons were similar in appearance to those found in the preoptic area of normal rats (Witkin and Silverman, 1985) and guinea pigs (Silverman and Witkin, 1985). The cells had a large central nucleus surrounded by a relatively thin rim of cytoplasm, the latter rich in rough endoplasmic reticulum, stacks of Golgi saccules, and mitochondria (Fig. 1). The nucleus contained 1 (Fig. 1) or 2 nucleoli, and the nuclear envelope was frequently indented (Fig. 1). Although cells were usually of the fusiform variety, 1 cell with a particularly irregular morphology was traced through several serial sections (Fig. 2). In this case, a major dendrite extended at right angles from the cell body, while the axon formed an acute angle with the dendrite. Reaction product within neurons was usually associated with some, but not all, stacks of rough endoplasmic reticulum and with the outer nuclear membrane (Fig. 1). In other cells, the reaction product had diffused throughout the cytoplasm and even into the nucleus (not shown). In many instances, there were obvious differences in the density of reaction product in different compartments of cells. As shown in Figure 2, immunoreaction product was concentrated within the initial axon segment and portions of a dendrite.

Evidence was found for a synaptic input to $\mathrm{GnRH}$ cells within the transplant. Such synapses were observed on the GnRH dendrites rather than the soma. However, since only a total of 6 cells were examined in detail, we cannot yet rule out the presence of an axosomatic input. The presynaptic elements observed in these preparations contained small, clear, round vesicles (Fig. 3 ). Because of the density of reaction product on the postsynaptic side, we could not identify these as symmetrical or asymmetrical contacts.

Many GnRH axon profiles were also found within the transplant. At the light-microscopic level these axons exited primarily from the transplant at the level of the host arcuate nucleus and median eminence as previously described (Silverman et al., 1985). Profiles of GnRH processes were found at the boundary between the transplant and host. The latter is rarely a solid barrier, but rather shows numerous gaps into which the cilia of ependymal cells derived from both host and implant project. $\mathrm{GnRH}$ processes at the boundary, and presumably crossing it, 

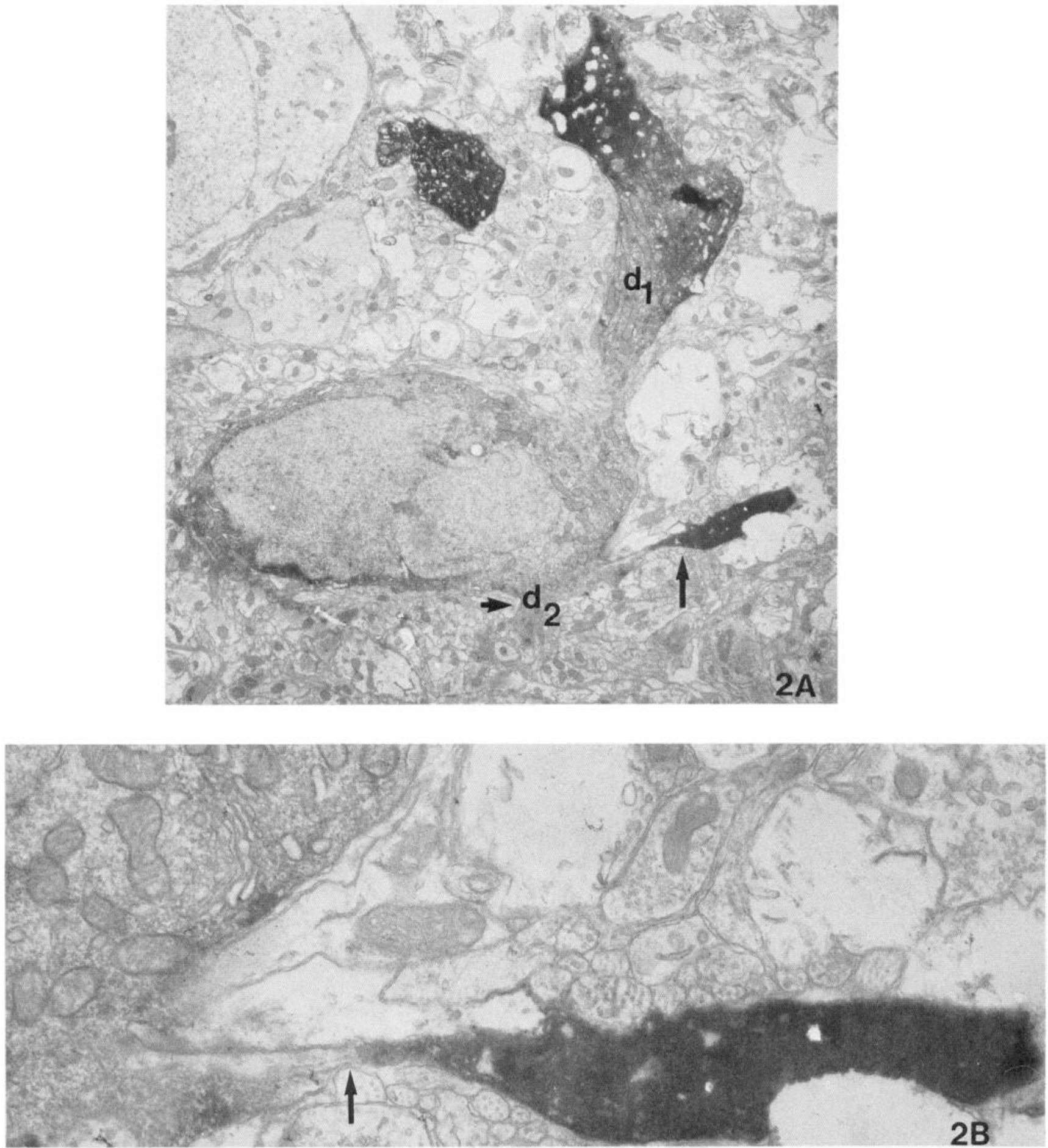

Figure 2. Very irregularly shaped GnRH neuron. The major dendrite $\left(d_{1}\right)$ is at a right angle from the soma, and the axon $(A)$ forms an acute angle with the dendrite. A small portion of a second dendrite is also present $\left(d_{2}\right)$. Note $(B)$ the dramatic difference in the density of reaction product between the soma and the axon and the soma and a portion of dendrite $d_{1} . A, \times 8000 ; B, 30,000$.

were found enveloped in glial/ependymal processes (Fig. 4).

GnRH axons that crossed into the host were numerous and were concentrated in the lateral edges of the median eminence over the tuberoinfundibular sulci. A fortuitous longitudinal section through an axon that could be followed through several serial sections remained next to a tanycyte process (Fig. 5a). This axon was found to terminate on a fenestrated capillary (Fig. $5 b$ ). It should be noted, however, that the vast majority of GnRH-positive axonal profiles were not in contact with the perivascular space.

\section{Discussion}

Transplants of normal fetal tissue have been used to correct the neuroendocrine deficit that results from a defective gene for the neurohormone GnRH. As in many of our previous studies (Krieger et al., 1982), testicular growth observed in the $h p g$ 

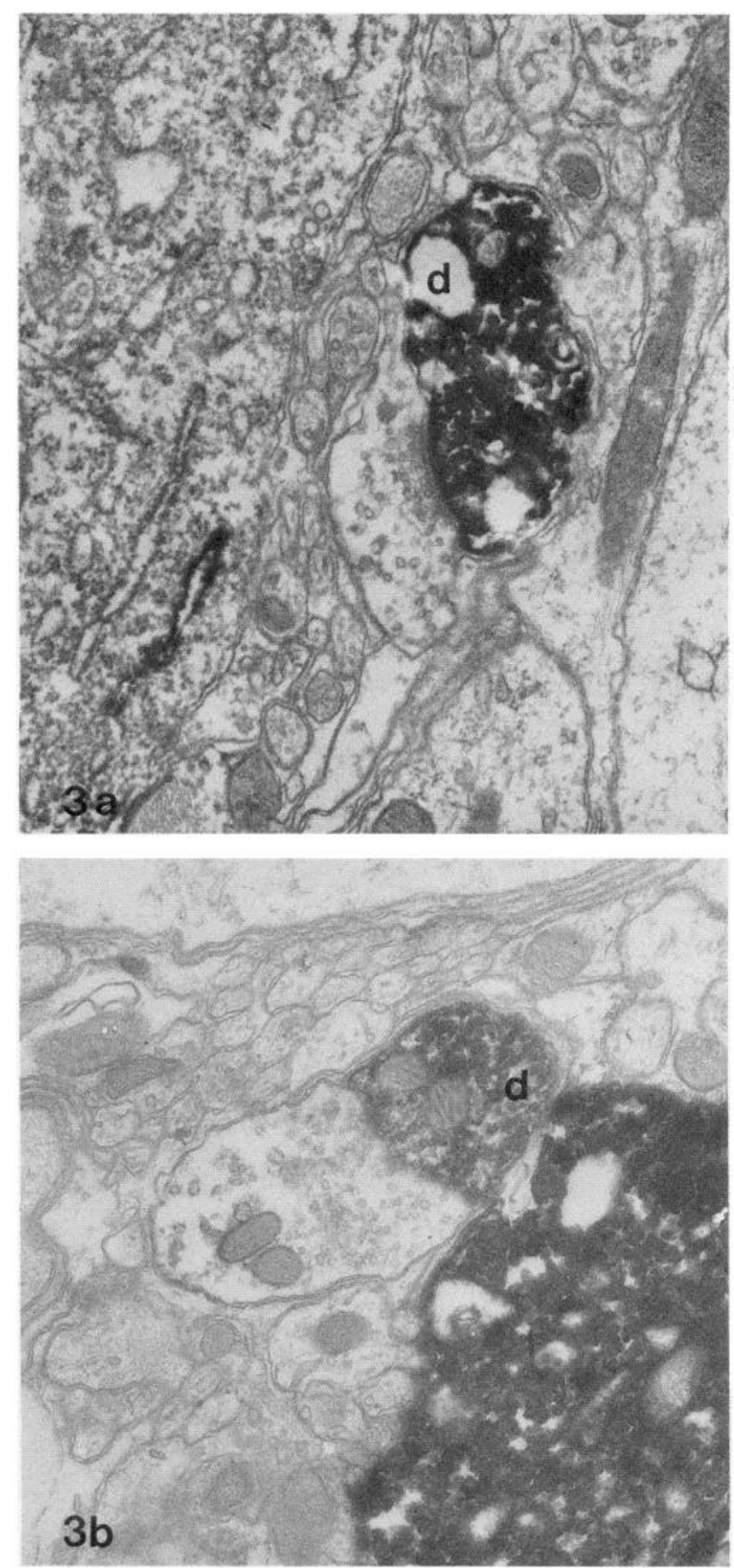

Figure 3. Examples of axodendritic synapses onto GnRH-positive dendrites. In both $a$ and $b$, the presynaptic element contains small, clear, round vesicles. $a, \times 30,000 ; b, \times 25,000$.

mutants with grafts is indicative of an increased level of function in the hypothalamo-pituitary gonadal axis. In this study, we examined tissue only from such successful grafts, since our aim was to analyze those features of graft-host integration that result in endocrine recovery. In previous studies immunocytochemical analysis suggested that implants failed to promote recovery of the pituitary-gonadal axis only if they were misplaced (not in the third ventricle) or degenerated (increased age of donor) (Silverman et al., 1985). We have had no instances in which a third ventricular graft containing GnRH neurons did not produce increased testicular or ovarian weight by $60 \mathrm{~d}$ postimplantation.

It is clear that the GnRH neurons present within the CNS graft retain a similar shape and distribution of reaction product to that found in other rodent GnRH neurons (Jennes et al., 1985; Witkin and Silverman, 1985). One of the interesting features is the abrupt change in the concentration of immunoreactive material from one compartment of the cell (soma) to the next (axon). This had been noted previously in the rat (Witkin and Silverman, 1985). In part this can be explained by differences in diffusion of materials into the depth of the tissue section. However, it is possible that either more antigen is stored at these sites or that processing of the precursor takes place within these regions, making the neuropeptide more accessible.

Although not numerous, synapses do occur onto the dendrites of these peptidergic neurons. A paucity of synapses, especially axosomatic synapses, is characteristic of the rat (Jennes et al., 1985; Kozlowski et al., 1980; Witkin and Silverman, 1985) but not the guinea pig (Silverman and Witkin, 1985). Whether the mouse follows the pattern of innervation seen in the rat remains to be determined. Although some of the synapses noted onto the GnRH neurons (or for that matter onto nonidentified cells and dendrites within the graft) may be of a local origin, others might originate from the host. Such host innervation of implants has been reported in other systems (e.g., Ebner et al., 1984; Harvey et al., 1982; Sotelo and Alvarado-Mallart, 1985). The possibility of heterologous input is strengthened by our recent observations that PNMT-positive fibers of the host enter the transplant in great abundance (E. A. Zimmerman, unpublished observations). Synapses that integrate the implant with the host CNS and that presumably also occur in grafts in female hosts might form part of the circuitry for the mating "induced" (stimulated) ovulations that can occur in these mice (Gibson et al., 1984b). A detailed quantitative comparison between the synaptic input for GnRH neurons in normal mouse preoptic area versus that for such neurons within the transplants is necessary to determine if the number and kind of synapses are similar in each.

Light-microscopic observations suggested that GnRH neurons followed the curving path of tanycytes of the medial basal hypothalamus (Silverman et al., 1985). This hypothesis is strengthened by our present observations. Axonal profiles at the boundary of the transplant and host are surrounded by glial or ependymal processes, and occasional fibers could be seen coursing next to tanycyte processes in the host median eminence. Whether these specialized ependyma and their arrangement within the medial basal hypothalamus are obligatory for axons to exit remains to be determined. Similarly, it is still unclear if, once leaving the boundary zone, axons always "follow" glial or ependymal processes and, if so, for how far toward the portal capillaries.

Axon terminals do indeed end on or near the perivascular space of portal capillaries, proving that they find their normal target. We rarely observed fiber outgrowth to regions other than the arcuate nucleus and median eminence. However, if grafts are placed within the lateral ventricle, then $\mathrm{GnRH}$ fibers that exit into the host find other appropriate pathways (i.e., stria terminalis and fornix), though arrival at other targets (i.e., medial amygdala) has not yet been demonstrated (Kokoris et al., 1984). As in normal animals (Goldsmith and Ganong, 1975; Silverman and Desnoyers, 1976), few neurosecretory terminals abut directly on the capillaries but rather are separated from them by glial processes of varying width. Whether movement of glial processes during times of increased release occurs in this system as it does in the posterior pituitary (Hatton et al., 1984) has not yet been studied. 

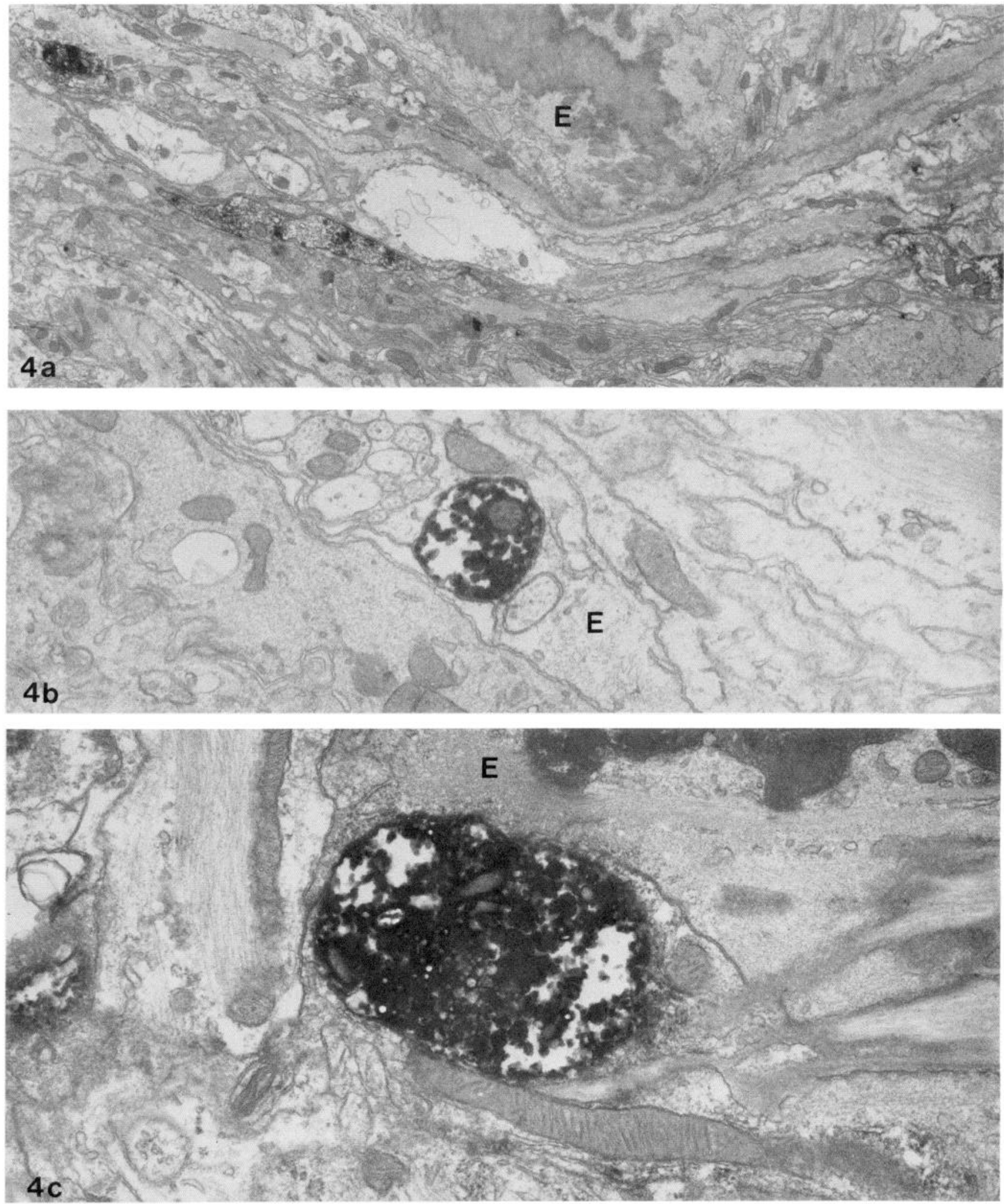

Figure 4. All 3 micrographs are of GnRH axons at the boundary zone crossing from graft into host. In all cases the immunoreactive axon is surrounded by glial/ependymal $(E)$ elements. $a, \times 7500 ; b$ and $c, \times 25,000$. 

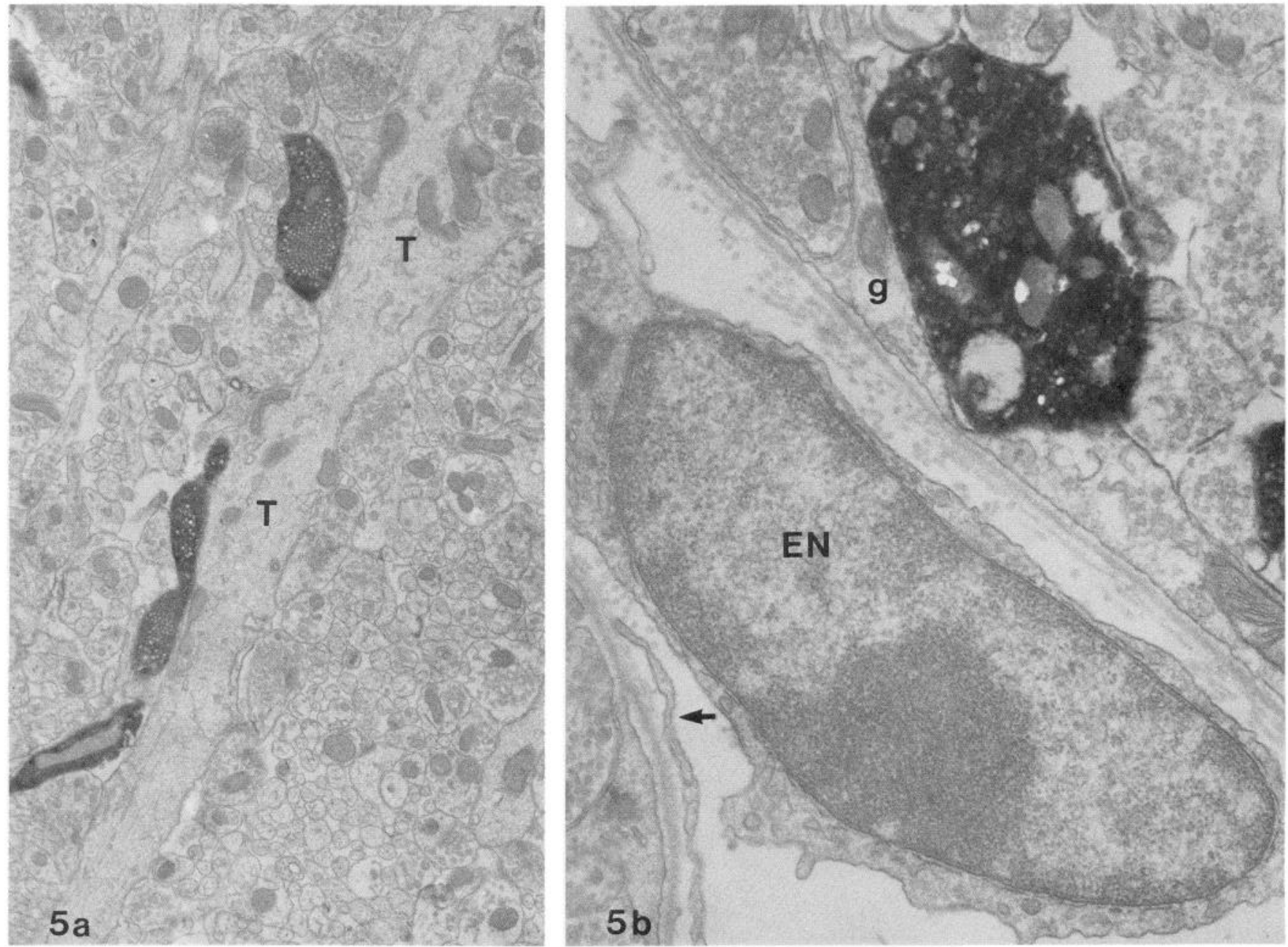

Figure 5. $a, \mathrm{GnRH}$ axon in the host median eminence. The axon courses next to a tanycyte $(T)$ for part of its length. $b$, A terminal abuts on a fenestrated capillary in the external zone of the median eminence but is separated from the perivascular space by a thin sheet of glial cytoplasm $(\mathrm{g})$. EN, Nucleus of endothelial cells of portal capillaries; arrow indicates fenestrated capillary cytoplasm.

\section{References}

Cattanach, B. M., C. A. Iddon, H. M. Charlton, S. A. Chiappa, and G. Fink (1977) Gonadotropin-releasing hormone deficiency in a mutant mouse with hypogonadism. Nature 269: 338-340.

Ebner, F. F., J. A. Olschowka, and D. M. Jacobowitz (1984) The development of peptide containing neurons within neocortical transplants in adult mice. Peptides 5: 103-113.

Gibson, M. J., H. M. Charlton, M. J. Perlow, E. A. Zimmerman, T. F. Davies, and D. T. Krieger (1984a) Preoptic area brain grafts in hypogonadal (hpg) female mice abolish effects of congenital hypothalamic gonadotropin-releasing hormone $(\mathrm{GnRH})$ deficiency. Endocrinology 114: 1938-1940.

Gibson, M. J., D. T. Krieger, H. M. Charlton, E. A. Zimmerman, A. J. Silverman, and M. J. Perlow (1984b) Mating and pregnancy can occur in genetically hypogonadal mice with preoptic area brain grafts. Science 225: 949-951.

Goldsmith, P. C., and W. F. Ganong (1975) Ultrastructural localization of LHRH in the median eminence of the rat. Brain Res. 97: 181193.

Harvey, A. R., G. T. Golden, and R. D. Lund (1982) Transplantation of tectal tissue in rats. III. Functional innervation of transplants by host afferents. Exp. Brain Res. 47: 437-439.

Hatton, G. I., L. S. Perlmutter, A. K. Salm, and C. D. Tweedle (1984) Dynamic neuronal-glial interactions in hypothalamus and pituitary: Implications for control of hormone synthesis and release. Peptides 5: $121-138$
Jennes, L., W. E. Stumpf, and M. E. Sheddy (1985) Ultrastructural characterization of gonadotropin-releasing hormone ( $\mathrm{GnRH})$-producing neurons. J. Comp. Neurol. 232: 534-547.

Kokoris, G. J., M. J. Perlow, M. S. Gibson, E. A. Zimmerman, A. J. Silverman, H. M. Charlton, and D. T. Krieger (1984) Effects of graft origin and site of transplantation on reversal of congenital hypogonadism by GnRH transplants. Soc. Neurosci. Abstr. 10: 373.

Kozlowski, G. P., L. Chu, G. Hostetter, and B. Kerdelhue (1980) Cellular characteristics of immunolabeled luteinizing hormone releasing hormone (LHRH) neurons. Peptides 1: 37-46.

Krieger, D. T., M. J. Gibson, E. A. Zimmerman, M. Ferin, H. M. Charlton, A. J. Silverman, and M. J. Perlow (1985) Correction of genetic gonadotropin releasing hormone deficiency by grafts of fetal preoptic area tissue. In Neural Grafting in the Mammalian CNS, A. Bjorklund and U. Stenevi, eds., pp. 645-653, Elsevier, New York.

Krieger, D. T., M. J. Perlow, M. J. Gibson, T. F. Davies, E. A. Zimmerman, M. Ferin, and H. M. Charlton (1982) Brain grafts reverse hypogonadism of gonadotropin releasing hormone deficiency. Nature 298: 468-471.

Oldfield, B. J., A. Hou-Yu, and A. J. Silverman (1983) Technique for the simultaneous ultrastructural demonstration of anterogradely transported horseradish peroxidase and an immunocytochemically identified neuropeptide. J. Histochem. Cytochem. 31: 1145-1150.

Silverman, A. J. (1984) Luteinizing hormone releasing hormone containing synapses in the diagonal band and preoptic area of the guinea pig. J. Comp. Neurol. 227: 452-458.

Silverman, A. J., and P. Desnoyers (1976) Ultrastructural immuno- 
cytochemical localization of luteinizing hormone-releasing hormone (LH-RH) in the median eminence of the guinea pig. Cell Tissue Res. 169: $157-166$.

Silverman, A. J., and J. W. Witkin (1985) Synaptic interactions of luteinizing hormone-releasing hormone (LHRH) neurons in the guinea pig preoptic area. J. Histochem. Cytochem. 33: 69-72.

Silverman, A. J., E. A. Zimmerman, M. J. Gibson, M. J. Perlow, H. M. Charlton, G. J. Kokoris, and D. T. Krieger (1985) Implantation of normal fetal preoptic area into hypogonadal mutant mice: Temporal relationships of the growth of gonadotropin-releasing hormone neurons and the development of the pituitary/testicular axis. Neuroscience 16: 69-85.
Sotelo, C., and R. M. Alvarado-Mallart (1985) Cerebellar transplants: Immunocytochemical study of the specificity of Purkinje cells inputs and outputs. In Neural Grafting in the Mammalian CNS, A. Bjorklund and U. Stenevi, eds., pp. 205-216, Elsevier, New York.

Witkin, J. W., and A. J. Silverman (1985) Synaptology of LHRH neurons in rat preoptic area. Peptides 6: 263-271.

Witkin, J. W., C. Paden, and A. J. Silverman (1982) The luteinizing hormone-releasing hormone (LHRH) systems in the rat brain. Neuroendocrinology 35: 429-438. 